\title{
Sticky siRNAs targeting survivin and cyclin B1 exert an antitumoral effect on melanoma subcutaneous xenografts and lung metastases
}

Valerie Kedinger ${ }^{1 *}$, Aline Meulle , Omar Zounib, Marie-Elise Bonnet ${ }^{1}$, Jean-Baptiste Gossart ${ }^{1}$, Elodie Benoit ${ }^{1}$, Melanie Messmer², Pattabhiraman Shankaranarayanan ${ }^{3}$, Jean-Paul Behr', Patrick Erbacher ${ }^{1}$ and Anne-Laure Bolcato-Bellemin ${ }^{4^{*}}$

\begin{abstract}
Background: Melanoma represents one of the most aggressive and therapeutically challenging malignancies as it often gives rise to metastases and develops resistance to classical chemotherapeutic agents. Although diverse therapies have been generated, no major improvement of the patient prognosis has been noticed. One promising alternative to the conventional therapeutic approaches currently available is the inactivation of proteins essential for survival and/or progression of melanomas by means of RNA interference. Survivin and cyclin B1, both involved in cell survival and proliferation and frequently deregulated in human cancers, are good candidate target genes for siRNA mediated therapeutics.
\end{abstract}

Methods: We used our newly developed sticky siRNA-based technology delivered with linear polyethyleneimine (PEI) to inhibit the expression of survivin and cyclin B1 both in vitro and in vivo, and addressed the effect of this inhibition on B16-F10 murine melanoma tumor development.

Results: We confirm that survivin and cyclin B1 downregulation through a RNA interference mechanism induces a blockage of the cell cycle as well as impaired proliferation of B16-F10 cells in vitro. Most importantly, PEl-mediated systemic delivery of sticky siRNAs against survivin and cyclin B1 efficiently blocks growth of established subcutaneaous B16-F10 tumors as well as formation and dissemination of melanoma lung metastases. In addition, we highlight that inhibition of survivin expression increases the effect of doxorubicin on lung B16-F10 metastasis growth inhibition.

Conclusion: PEl-mediated delivery of sticky siRNAs targeting genes involved in tumor progression such as survivin and cyclin B1, either alone or in combination with chemotherapeutic drugs, represents a promising strategy for melanoma treatment.

Keywords: Sticky siRNA, Delivery, Survivin, Cyclin B1, Tumor inhibition, Melanoma

\section{Background}

Melanoma is considered as one of the most aggressive human cancers. The majority of melanoma-associated deaths are caused by metastases, which can occur in a wider variety of areas than any other cancer [1]. Among target organs, the lung represents a common site of metastasis,

\footnotetext{
*Correspondence: vkedinger@polyplus-transfection.com; al_bolcato@yahoo.com 'Polyplus-transfection SA, Bioparc, BP 90018, Boulevard Sébastien Brant, 67401 Illkirch, France

${ }^{4}$ Current address: Quintiles, rue Jean Dominique Cassini, BP 50137, 67404 Illkirch Cedex, France

Full list of author information is available at the end of the article
}

mostly because of its anatomic structure and high vascularization. These characteristics make it a preferential pathway for metastatic seeding and a rich environment for neoplastic growth [2]. Another feature commonly attributed to melanoma is its chemo-resistance [3]. During melanoma progression, the breakdown of cell death control leading to resistance to chemotherapeutic drugs is achieved through the combined activation of anti-apoptotic factors, inactivation of pro-apoptotic effectors and reinforcement of survival signals. Targeting one or more of these different factors may be a key requisite to overcome drug resistance

\section{Biomed Central}


and thus improve clinical outcome of patients with melanoma.

Survivin, a member of the Inhibitor of Apoptosis Protein (IAP) family [4], has emerged few years ago as a promising therapeutic target in cancers because of its overexpression in a wide spectrum of tumors, including melanoma [5-7]. Additionally, survivin was identified as a marker of poor prognosis in melanoma [8]. In addition to its role in apoptosis inhibition, survivin also plays a critical role in the regulation of cell division by inducing exit from G1 checkpoint arrest and subsequent entry into $S$ phase [9]. Finally, recent studies have involved survivin in cell motility, which may underlie a role for this protein in promoting melanoma metastasis [10-12]. Various approaches involving molecular inhibitors have been developed to inhibit its expression in tumor cells [6,13-17]. Another potential therapeutic target for cancer treatment is represented by cyclin B1, the regulatory subunit of cyclin-dependent kinase 1 (cdk1), which plays a pivotal role in the transition of the cell cycle from G2 phase to mitosis [18]. Altered expression of cyclin B1 has been reported in numerous cancers, where it could contribute to chromosomal instability [19-23]. Furthermore, several studies have demonstrated its clinical significance as a poor prognosis factor for several cancer types [24-27], including melanoma [28], and cyclin B1 overexpression is responsible for radiotherapy resistance in different tumors [29-31].

RNA interference represents a powerful approach for antitumor therapy by allowing in vivo silencing of essential genes for tumor progression and provides a promising alternative to traditional small molecule therapies. However, delivery of siRNAs still remains the most challenging step for the development of a siRNA-based therapy. The challenge includes efficient target gene silencing in the desired tissue while avoiding side effects such as immune response, toxicity and off-target silencing. In this context, the cationic linear polyethylenimine (PEI) is well known for its efficiency to transfect genes both in vitro and in vivo as it is involved in several clinical trials for the treatment of bladder cancer (http://clinicaltrials.gov/ct2/ show/NCT00595088), pancreatic ductal adenocarcinoma (http://clinicaltrials.gov/ct2/show/NCT01274455) and multiple myeloma (http://clinicaltrials.gov/ct2/ show/NCT01435720?term=senesco\&rank=1). In this study, we investigated its ability to deliver functional antitumoral siRNA. To this end, we have developed sticky siRNAs (ssiRNAs) that mimic gene structure through reversible concatemerization brought by sticky 3'-complementary overhangs [32]. These modified siRNAs confer a higher stability to the complexes formed with linear PEI, thus increasing gene silencing efficiency both in vitro and in vivo, compared with standard siRNAs. We used this new technology to specifically target survivin and cyclin B1 in B16-F10 murine melanoma cells. Our results show that ssiRNAs are efficient to inhibit survivin and cyclin B1 expression in vitro and that a systemic treatment with ssiRNAs targeting these two genes is able to reduce both subcutaneous melanoma tumors and their lung metastases. Moreover, inhibition of survivin expression increased the effect of a doxorubicin treatment on melanoma lung metastasis. Altogether, our data are promising towards development of ssiRNAs against survivin and cyclin B1 as a new therapeutic strategy for melanoma treatment.

\section{Methods \\ Cell line}

Murine melanoma B16-F10 cell line was obtained from ATCC and cultured in Dulbecco's modified Eagle's medium (Eurobio, Courtaboeuf, France), supplemented with $10 \%$ fetal bovine serum (Hyclone, Logan, UT, USA), $2 \mathrm{mM}$ Glutamine (Eurobio) and $200 \mathrm{U} / \mathrm{ml}$ penicillin / $200 \mu \mathrm{g} / \mathrm{ml}$ streptomycin (Eurobio).

\section{Sticky siRNAs}

IEX-HPLC-purified nucleic acids were purchased from Eurogentec (Brussels, Belgium). Annealing was performed in annealing buffer (Eurogentec), final concentration $0.1 \mathrm{X}$ for $2 \mathrm{~min}$ at $95^{\circ} \mathrm{C}$ followed by slow cooling. Sequences were as follow:

Cyclin B1 ssiRNA sense, 5'-GAGAUGUACCCUCCA GAAAdTdTdTdTdTdTdTdT-3',

Cyclin B1 ssiRNA antisense, 5'-UUUCUGGAGGGUA CAUCUCdAdAdAdAdAdAdAdA-3',

Survivin ssiRNA sense, 5'-CCGUCAGUGAAUUCUU GAAdTdTdTdTdTdTdTdT-3',

Survivin ssiRNA antisense, 5'-UUCAAGAAUUCACU GACGGdAdAdAdAdAdAdAdA-3',

Negative control ssiRNA sense, 5'-AUGUCUACUGG CAGUCCUGdTdTdTdTdTdTdTdT-3',

Negative control ssiRNA antisense, 5'-CAGGACUGC CAGUAGACAUdAdAdAdAdAdAdAdA-3'.

\section{In vitro and in vivo transfections}

jetPEI ${ }^{\oplus}$ and in vivo-jetPEI ${ }^{\oplus}$ were from Polyplus-transfection (Illkirch, France). For transfection with jetPEI ${ }^{\odot}$ reagent, complexes were prepared as follows: for a triplicate experiment, the required amount of ssiRNA and transfection reagent were each separately diluted in $150 \mu \mathrm{l}$ of $\mathrm{NaCl} 150$ $\mathrm{mM}$. A volume of $2.4 \mu \mathrm{l}$ (for $75 \mathrm{nM}$ of ssiRNA, $\mathrm{N} / \mathrm{P}=6$ ) or $3.2 \mu \mathrm{l}$ (for $50 \mathrm{nM}$ of ssiRNA, N/P=8) of jetPEI ${ }^{\circ}$ was used per $\mu \mathrm{g}$ of siRNA. N/P ratio is defined as the number of nitrogen residues of jetPEI ${ }^{\oplus}$ per nucleic acid phosphate. The transfection reagent solution was added to the ssiRNA solution and left for $30 \mathrm{~min}$ at room temperature. A volume of $100 \mu \mathrm{l}$ of complexes was added to B16-F10 cells seeded in 24-well plates at 40,000 cells/well one day before, and placed in $0.5 \mathrm{ml}$ of medium without serum just prior to complexes addition. After $4 \mathrm{~h}$, the medium 
was replaced by $1 \mathrm{ml}$ of complete medium containing 10\% serum.

For in vivo delivery with in vivo-jetPEI ${ }^{\circ}$, complexes were prepared as follows: for 1 mouse, the required amount of nucleic acid and PEI were separately diluted in $100 \mu \mathrm{l}$ of $5 \%$ glucose solution (final concentration). For injection of 0.6 $\mathrm{mg} / \mathrm{kg}$ of ssiRNA, $0.16 \mu \mathrm{l}$ of PEI were used per $\mu \mathrm{g}$ of ssiRNA ( $/ \mathrm{P}=8)$. For the $1 \mathrm{mg} / \mathrm{kg}$ ssiRNA injected amount, $0.25 \mu \mathrm{l}$ of PEI were used per $\mu \mathrm{g}$ of ssiRNA $(\mathrm{N} / \mathrm{P}=12.5)$. The transfection reagent solution was added to the ssiRNA solution and left for at least $30 \mathrm{~min}$ at room temperature. At this stage complexes are stable for more than $4 \mathrm{~h}$ at room temperature.

\section{Animal experiments}

All animal studies were conducted in accordance to the French Animal Care guidelines and the protocols were approved by the Direction des Services Vétérinaires. Five-weeks old NMRI Nude female mice were obtained from Elevage Janvier (Le Genset Saint Isle, France). For subcutaneous xenografts, B16-F10 cells $\left(1 \times 10^{6}\right.$ cells in $100 \mu \mathrm{l}$ of culture medium without serum) were injected subcutaneously on the right flank of animals. ssiRNA/ PEI complexes were intravenously injected through the retro-orbital sinus within 2 s. Treatment with ssiRNA complexes started when tumors reached $50 \mathrm{~mm}^{3}$ and were performed every other day until sacrifice of the animals. Tumors were measured at each injection, and tumor volume was calculated as $v=\left(\pi \times \mathrm{L} \times \mathrm{l}^{2}\right) / 6$. For lung metastasis model, B16-F10 cells $\left(1 \times 10^{6}\right.$ cells in $300 \mu \mathrm{l}$ of culture medium without serum) were injected intravenously through the tail vein.

\section{Branched DNA assay}

QuantiGene assay (Panomics, Santa Clara, CA, USA) was used to quantify the amount of mRNA in cells or lungs. Cells were lysed in $600 \mu \mathrm{l}$ of $1 \times$ lysis buffer and incubated for $30 \mathrm{~min}$ at $50^{\circ} \mathrm{C}$. Lungs were lysed in $20 \mathrm{ml}$ of tissue and cell lysis solution (Tebu, Le Perray-en-Yvelines, France), supplemented with $0.15 \mathrm{mg} / \mathrm{ml}$ of $\mathrm{K}$ Proteinase (Sigma-Aldrich, St Louis, MO, USA) and incubated three times $5 \mathrm{~min}$ at $60^{\circ} \mathrm{C}$ with $10 \mathrm{~s}$ vortexing. A volume of $1-$ $60 \mu \mathrm{l}$ of cell or lung lysate was used for branched DNA (bDNA) assay. Probe set were designed using QuantiGene ProbeDesigner software. Target gene expression was assayed according to manufacturer recommendations. Target expression level was normalized to corresponding GAPDH expression from the same cell lysate.

\section{Western blot analysis}

Cells were lysed in $100 \mu \mathrm{l}$ of RIPA buffer. Proteins were quantified with the BCA kit (Pierce, Brebieres, France). Fifty micrograms of total protein were subjected to electrophoresis on a 10 or $15 \%$ acrylamide/bisacrylamide gel and transferred to a poly (vinylidene fluoride) membrane (Millipore, Molsheim, France). A mouse anti-cyclin B1 monoclonal antibody (Cell Signaling Technologies, Danvers, MA, USA) at $1 / 1,000$, a rabbit anti-survivin polyclonal antibody (Cell Signaling Technologies) at 1/ 1,000 and a mouse anti-GAPDH monoclonal antibody (Ambion, Austin, TX) at 1/10,000 were used. Antirabbit or anti-mouse secondary horseradish peroxidaseconjugated were purchased from Millipore and used at $1 / 10,000$. Protein bands were visualized with enhanced chimioluminescence reagent (ECL, Amersham, GE Healthcare, Velizy-Villacoublay, France).

\section{Proliferation assay}

Cell pellets were homogenized in $100 \mu \mathrm{l}$ of 1:1 PBS/trypan blue (Eurobio) and live cells were counted using an automatic hematocyter (TC10, BioRad, Marnes-la-Coquette, France).

For nuclei morphology analysis, cells were fixed with ice-cold methanol for $10 \mathrm{~min}$, rinsed with $1 \times \mathrm{PBS}$ and stained with DAPI $(0.01 \mu \mathrm{g} / \mu \mathrm{l})$ for $15 \mathrm{~min}$. Cells were observed using a Nikon inverted microscope (Nikon Eclipse TE 2000-S, Amsterdam, Netherland).

\section{Cell cycle and apoptosis analysis}

Cells were fixed in chilled $50 \%$ ethanol for $15 \mathrm{~min}$ at $-20^{\circ} \mathrm{C}$. Pellets were incubated in $1 \times$ PBS with $0.1 \%$ Triton X-100 and $5 \% \mathrm{BSA}$ for $10 \mathrm{~min}$ on ice, and for $30 \mathrm{~min}$ at $37^{\circ} \mathrm{C}$ in $1 \times$ PBS containing $20 \mu \mathrm{g} / \mathrm{ml}$ of RNase A. Propidium iodide $(100 \mu \mathrm{g} / \mathrm{ml})$ was added for $10 \mathrm{~min}$ at room temperature. Cell pellet was resuspended in $1 \times$ PBS, 5 mM EDTA to obtain a cell concentration lower than $5.10^{5}$ cells $/ \mathrm{ml}$. Cells were analyzed by FACS using a Guava apparatus from Millipore (Molsheim, France).

\section{5'-RACE analysis}

Total RNA was isolated using RNA NOW reagent (Biogentex Laboratories, Houston, TX, USA) following instructions of the manufacturer. One $\mu \mathrm{g}$ of RNA was ligated to GeneRacer ${ }^{\text {ma }}$ RNA Oligo (5'-CGA-CUG-GAGCAC-GAG-GAC-ACU-GAC-AUG-GAC-UGA-AGGAGU-AGA-AA-3'; Life Technologies, Saint Aubin, France). Two-hundred and fifty nanograms of Oligo were used respectively for cyclin B1 or survivin analysis. Ligated RNA was reverse transcribed using a gene-specific primer (Table 1). To detect the cleavage product, one or two rounds of consecutive PCR (for conditions see Additional

Table 1 Primers used for Reverse transcription

\begin{tabular}{ll}
\hline Name & Sequence \\
\hline Cyclin B1 Rev (CCNBM1548R) & 5'-TTC-GAC-AAC-TTC-CGT-TAG-CC-3' \\
Survivin Rev (810R) & 5'-AGC-TCT-GGA-CTC-TGG-CCA-CCC-3' \\
\hline
\end{tabular}


Table 2 Primers used for PCR

\begin{tabular}{ll}
\hline Name & Sequence \\
\hline Cyclin B1 Rev (CCNBM975R) & 5'-AGG-GCG-ACC-CAG-GCT-GAA-GT-3' \\
Survivin Rev (810R) & 5'-AGC-TCT-GGA-CTC-TGG-CCA-CCC-3' \\
Survivin RevN (743R) & 5'-GCC-ACC-TCC-CTG-TGG-ACT-CA-3' \\
\hline
\end{tabular}

file 1: Table S1) were performed using primers complementary to the RNA Oligo and to cyclin B1 or survivin gene sequence (Table 2).

\section{Histology}

After mice sacrifice, lungs were perfused with $4 \%$ paraformaldehyde, incubated for $16 \mathrm{~h}$ in $4 \%$ paraformaldehyde and processed for paraffin embedding. Paraffin sections $(7 \mu \mathrm{m})$ were generated and Hematoxylin/Eosin (H\&E) stained.

\section{Statistical analysis}

All statistical analyses were performed using GraphPad prism software package (version 5). P values were calculated according to Mann-Withney test and were considered significant when lower than 0.05.

\section{Results and discussion}

in vitro ssiRNAs gene silencing efficiency in B16-F10 murine melanoma cells

We used previously validated survivin and cyclin B1 siRNA sequences [33,34], designed sticky siRNAs with these sequences by adding 3' complementary overhangs and first tested their silencing efficiency both at the mRNA and protein levels in B16-F10 cells. A sequence presenting no homology with mRNA databases was used as a negative control. Transfection of B16-F10 cells with jetPEI ${ }^{\odot}$ and different concentrations of specific ssiRNAs ranging from 25 to $100 \mathrm{nM}$ was performed and all led to a significant reduction of cyclin $\mathrm{B} 1$ and survivin mRNA control cells ssiRNA negative control ssiRNA Survivin

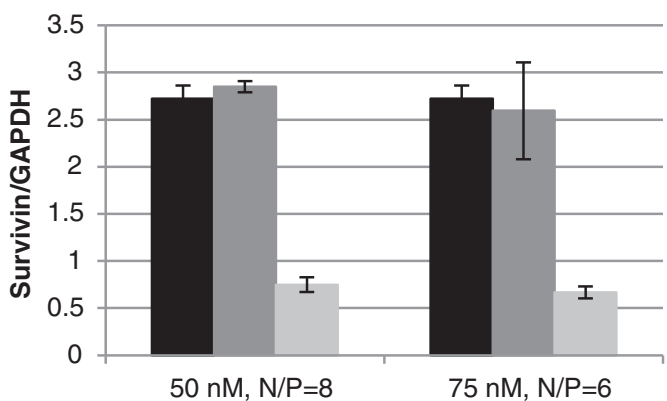

C
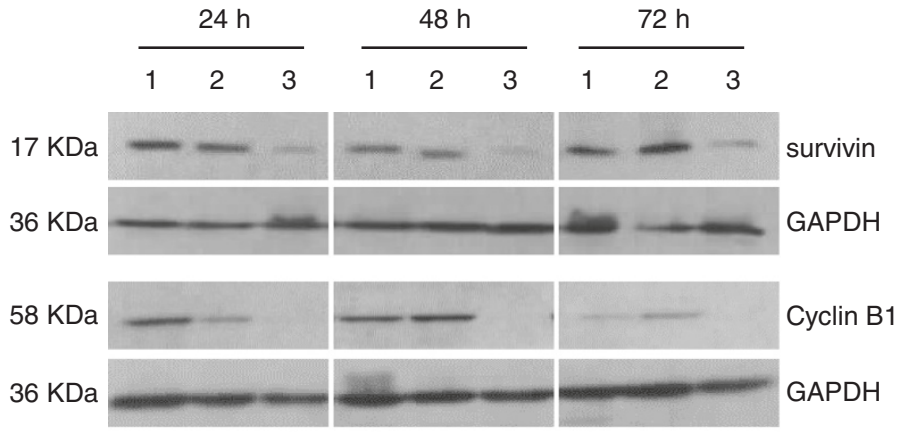

b

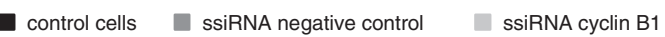

d

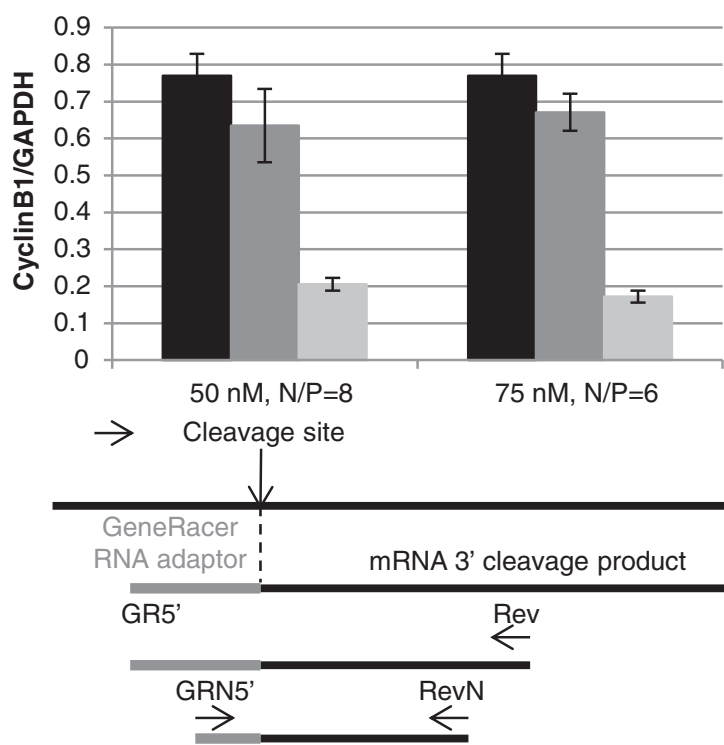

Final 5'-RACE PCR product
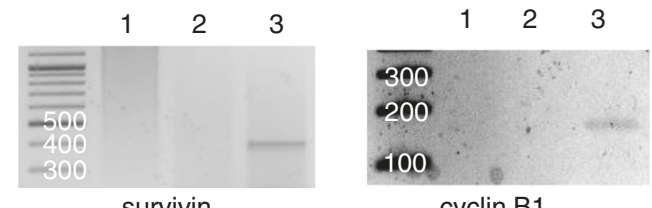

cyclin B1

Figure 1 Inhibition of survivin and cyclin B1 expression in B16-F10 cells. (a, b) mRNA expression level of cyclin B1 and survivin analyzed by branched DNA $16 \mathrm{~h}$ after transfection with ssiRNAs and PEI. Cyclin B1 and survivin levels are expressed relative to GAPDH. (c) Protein level of cyclin B1 and survivin analyzed by Western blot 24, 48 and $72 \mathrm{~h}$ after transfection with a negative control ssiRNA (2) or ssiRNAs against cyclin B1 or survivin (3) (50 nM, N/P=8). Non transfected cells (1) were also loaded. GAPDH was used as a loading control. (d) In vitro 5'-RACE analysis of RNA extracted from B16-F10 cells either untransfected (1) or $16 \mathrm{~h}$ after transfection with negative control (2), cyclin B1 or survivin (3) ssiRNAs and PEI (50 nM, N/P 8). Top part, schematic representation of the 5'-RACE procedure. 
levels. The level of inhibition was optimal at $50 \mathrm{nM}, \mathrm{N} / \mathrm{P}$ of 8 and $75 \mathrm{nM}, \mathrm{N} / \mathrm{P}$ of 6 (Figure $1 \mathrm{a}$ and b). Indeed, both concentrations induced a 70 to $80 \%$ inhibition of the two target mRNA expression compared to control cells. This downregulation of mRNA expression induced a diminution of the corresponding protein level for at least $48 \mathrm{~h}$ for both target proteins, as analyzed by Western blot (Figure 1c).

In order to confirm that the gene silencing observed after transfection occurred through a RNAi mechanism, we then performed rapid amplification of cDNA ends (5'-RACE) on RNAs extracted from B16-F10 cells transfected with cyclin B1, survivin or negative control ssiRNA. A band corresponding to the predicted cleavage product (158 bp for cyclin B1 and 330 bp for survivin) was specifically detected from RNAs extracted of both cyclin B1 and survivin
ssiRNA transfected cells (Figure 1d). Sequencing analysis of the PCR products confirmed their specificity (data not shown).

The inhibition of cyclin B1 and survivin expression observed after ssiRNA transfections was accompanied by a specific cellular effect, as cells presented a growth inhibition of more than $80 \%$ compared to control cells $48 \mathrm{~h}$ post-transfection (Figure 2a). The proliferation rate of cells transfected with the negative control ssiRNA was also somewhat lowered compared to control cells. This diminution can be attributed to the transfection itself, which causes a transient blockage of the cell cycle progression. To further characterize the growth inhibition induced by the down-regulation of both cyclin B1 and survivin, we analyzed by flow cytometry B16-F10 DNA content $48 \mathrm{~h}$ after transfection of ssiRNAs (Figure $2 \mathrm{~b}$ ).

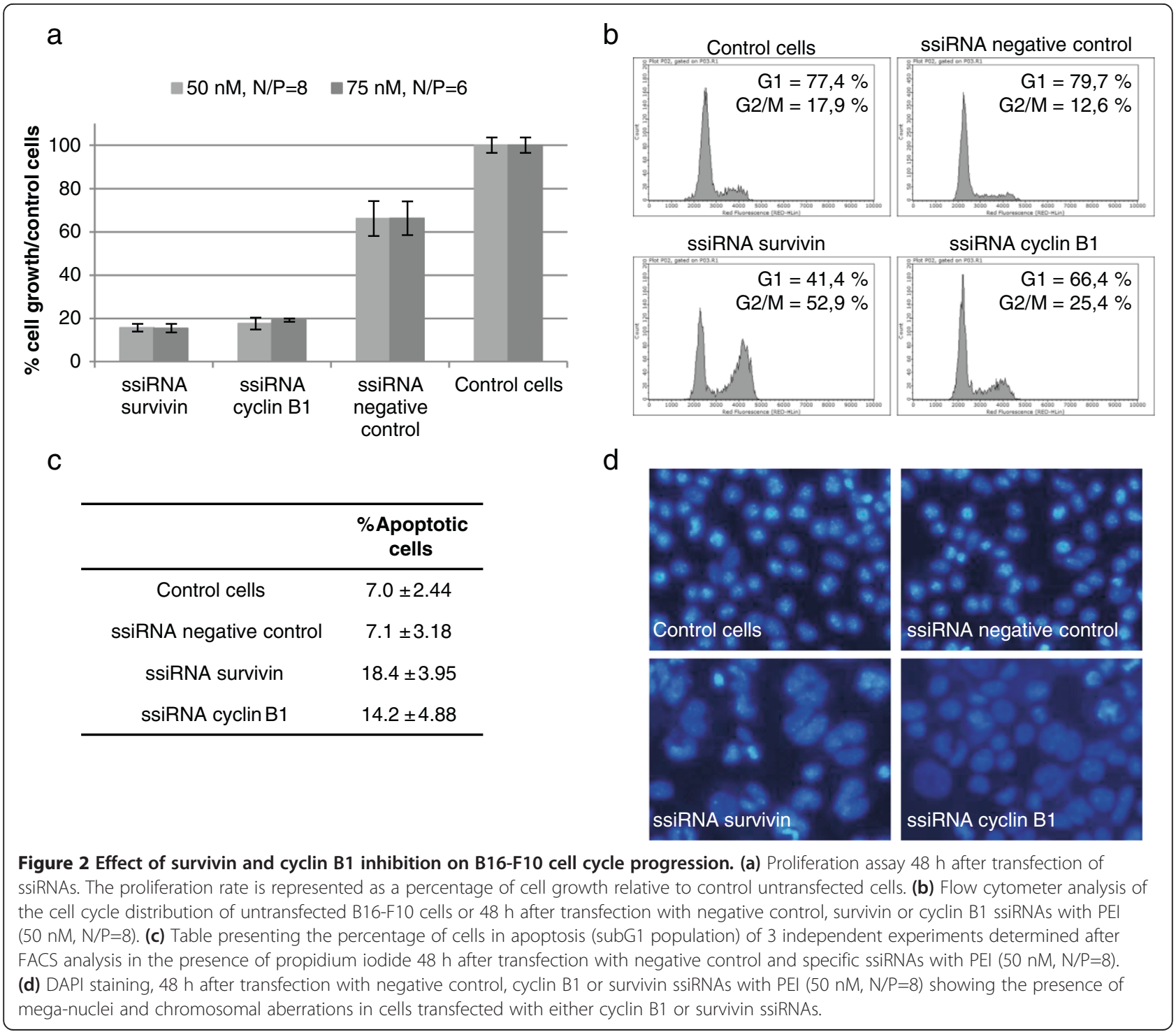


Whereas only 17.9 and $12.6 \%$ of nontransfected or negative control ssiRNA-transfected cells were located in G2/M phase, respectively, more than $50 \%$ of cells transfected with survivin ssiRNA were arrested in G2/M phase. Comparatively, the effect was milder after cyclin B1 inhibition, yet a significant blockage of the cells in G2/M phase was still present (Figure $2 \mathrm{~b}$ ). Moreover, percentage of apoptotic cells was also increased following downregulation of survivin and cyclin B1 expression compared to controls (Figure 2c). Finally, DAPI staining of cells in which cyclin B1 or survivin expression was inhibited showed a high proportion of cells presenting mega-nuclei (more than $50 \%$ of the cells), a characteristic of cell cycle arrest (Figure $2 \mathrm{~d}$ ).

Altogether, these results validate the ssiRNA approach to silence cyclin B1 and survivin through a mechanism of RNA interference in vitro in B16-F10 murine melanoma cells.

\section{Systemic treatment with ssiRNAs inhibits growth of} established subcutaneous melanoma xenografts

B16-F10 cells have the ability to form tumors when injected subcutaneously in nude mice [35]. We took advantage of this model mimicking a primary melanoma tumor to test the potency and specificity of PEI-mediated delivery of ssiRNAs in vivo. First, in order to confirm a RNA interference mechanism of ssiRNAs in vivo, we performed a 5'-RACE analysis after intra-tumoral injection of ssiRNA $(0.6 \mathrm{mg} / \mathrm{kg}, \mathrm{N} / \mathrm{P}=8)$ complexed with in vivo-jetPEI ${ }^{\circ}$. As shown in Figure $3 \mathrm{a}$, we detected a band specific for the cleavage product after injection of either cyclin B1 or survivin ssiRNAs in B16-F10 xenografts that could not be detected in glucose or negative control ssiRNA injected tumors.

We then assessed the effect of a systemic treatment of ssiRNAs delivered with in vivo-jetPEI ${ }^{\ominus}$ on the growth of B16-F10 xenografts. Intravenous delivery of ssiRNAs at $1 \mathrm{mg} / \mathrm{kg}(\mathrm{N} / \mathrm{P}=12.5)$ was performed every other day. The mean tumor size monitored after each injection is represented in Figure $3 \mathrm{~b}$ for each group. We started to observe a reduction of tumor growth after the third injection of ssiRNA against survivin (i.e., 5 days after tumor cells injection), which persisted until the end of the experiment and reached a significant inhibition of up to $50 \%$ compared to control mice (Figure $3 \mathrm{~b}$ ). The effect of cyclin B1 ssiRNA was less pronounced, yet still significant as it leads to $44 \%$ inhibition of tumor growth compared to controls (Figure 3c). The difference

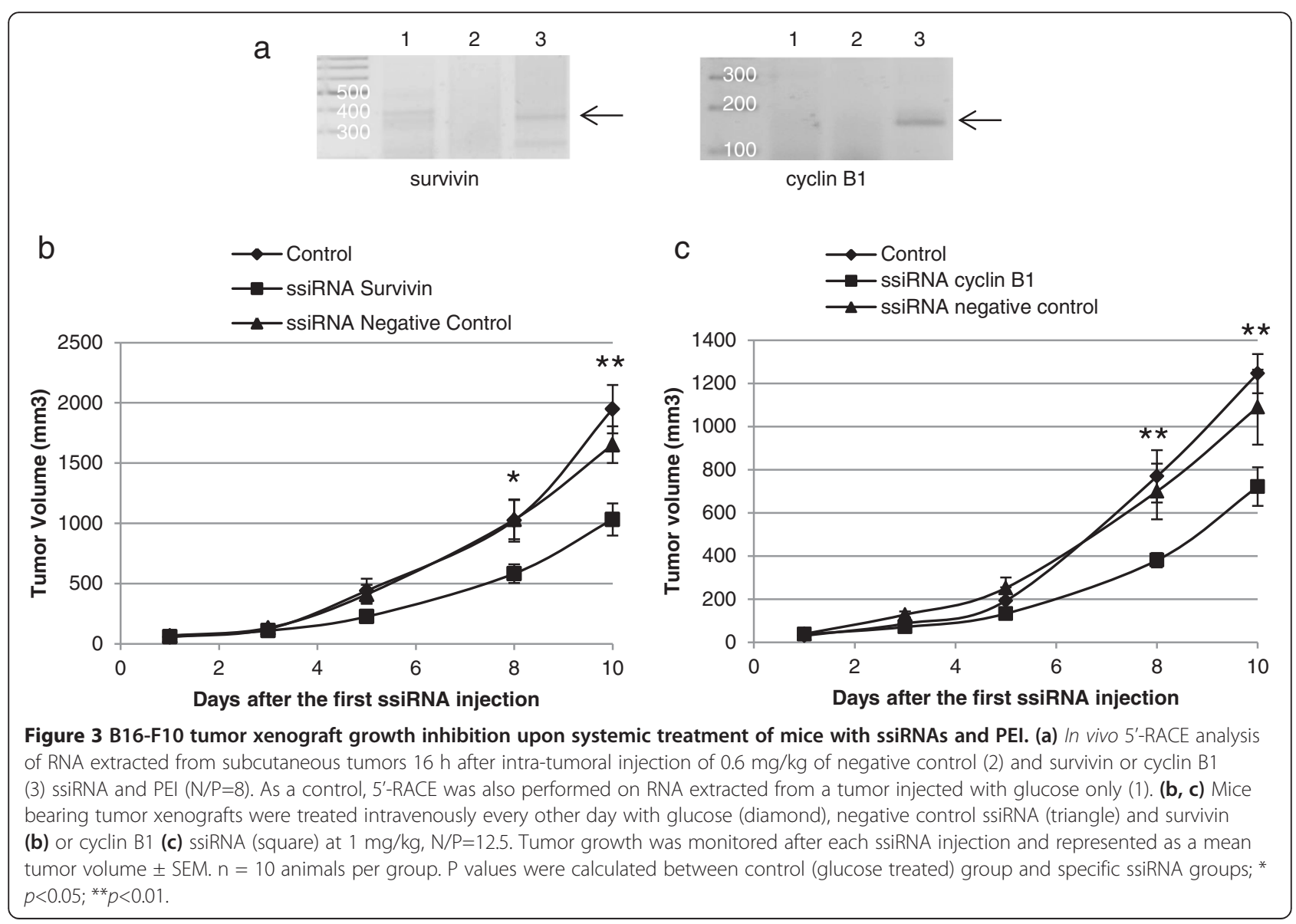


observed between the two target genes could be explained by the multifunctionality of survivin compared to cyclin B1, as the first protein is implicated in apoptosis, proliferation and motility [36], whereas the second one only plays a critical role in the control of the cell cycle progression and apoptosis [18]. The mice treated with negative control ssiRNA presented a minor, statistically nonsignificant, reduction of tumor size. The difference between the control and negative control ssiRNA groups could reflect the nonspecific effect of transfection on the cell cycle previously observed in vitro (see above).

\section{Melanoma lung metastases are reduced following} systemic treatment with ssiRNAs

Metastases, which represent the leading cause of mortality for patients with melanoma, are the most challenging cells to target. PEI was previously shown to preferentially deliver active nucleic acids, plasmids and siRNAs, to the lung after intravenous injection [37-40]. We therefore wondered whether systemic treatment of antitumoral ssiRNAs delivered with PEI could reduce the formation of melanoma lung metastases. When injected into nude mice tail vein, B16-F10 cells rapidly give rise to lung metastases. The advantage of this model is that it circumvents the initial step of tumor cell migration and allows us to evaluate the effect of our treatment on the implantation of metastatic cells in the host tissue and their subsequent proliferation. Treatment with ssiRNAs was performed as described in Figure 4a. At the end of the experiment, lungs were excised and observed for metastatic nodules. Treatment with cyclin B1 and survivin specific ssiRNAs led to an important reduction of the number of metastases (black nodules) compared to controls as illustrated by representative pictures of lungs (Figure $4 \mathrm{~b}$ ). The lung weight

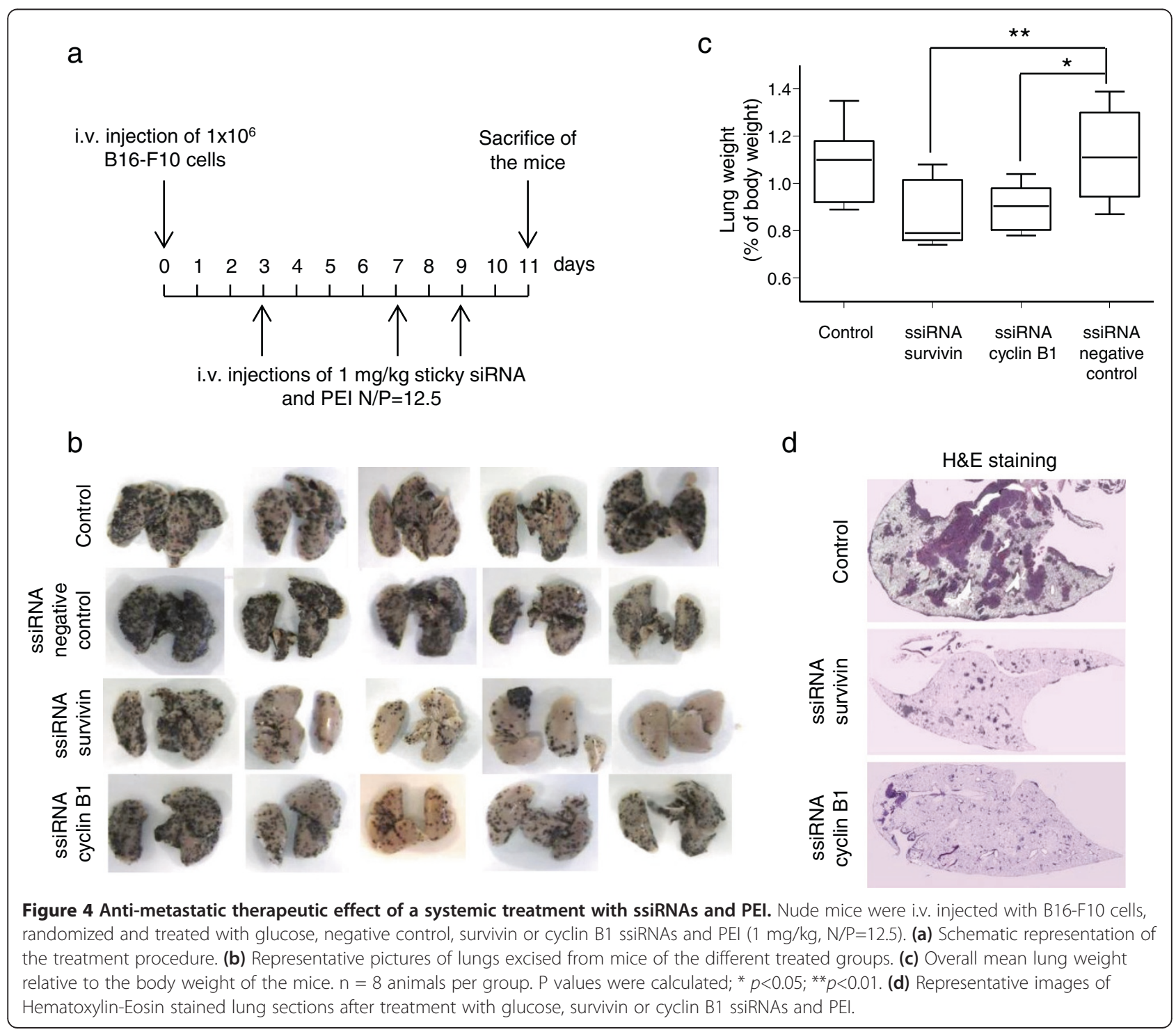


was also used as an indicator of metastasis progression. We determined the mean percentage of lung over body weight in each group and observed a significant decrease in groups treated with survivin and cyclin B1 ssiRNAs compared to control groups (Figure 4c). Histological analysis of lung sections was performed which further confirmed the drastic diminution of both nodule size and number in both survivin and cyclin B1 ssiRNA treated lungs (Figure 4d).

Even if representative of the metastatic grade, lung weight evaluation is not the best quantitative method, and probably leads to an underestimation of the effect produced by the ssiRNAs injection. Indeed, with this method only 20 and $25 \%$ reduction of lung tumor weight were observed following cyclin B1 and survivin ssiRNA treatment, respectively. We thus developed a quantitative assay based on MITF dosage. Indeed, as MITF is a melanocyte specific transcription factor [41], it allows quantification of the B16-F10 nodules present in the lungs. When MITF expression is detected in lungs, its level should be directly proportional to the number of B16-F10 tumor cells. To verify this hypothesis, we analyzed MITF mRNA level in lungs containing increasing number of B16-F10 tumors (Figure 5a). As expected, no MITF mRNA was observed in lungs without B16-F10 tumors. In lungs presenting an intermediate number of B16-F10 tumors, an intermediate level of MITF was observed, whereas in lungs with a high level of tumor cells, a high level of MITF was observed (Figure 5a). In addition, we validated the linearity of our MITF assay (see Additional file 2: Figure S1).

We then looked at the MITF mRNA level in lungs of ssiRNA-treated mice, and observed a significant diminution after either survivin or cyclin B1 ssiRNA systemic treatment compared to the level of MITF present in lungs of glucose or negative control ssiRNA treated mice (65 and 56\% inhibition compared to negative control ssiRNA, respectively, Figure 5b). These results are in better agreement with our macroscopic and microscopic observations, and confirm the anti-metastatic effect of a systemic treatment of mice with ssiRNAs targeting genes implicated in the cell cycle regulation.

\section{Alternated treatment with doxorubicin and survivin ssiRNA induces an additive diminution of melanoma lung metastases}

The poor prognosis attributed to melanomas largely results from resistance to conventional chemotherapy $[3,42]$. Doxorubicin, a topoisomerase II inhibitor, has been used for years to treat diverse types of cancers, and it is one of the most effective anticancer drugs currently known. However, its clinical use is limited by dosedependent toxicity, low specificity against cancer cells and emergence of resistance [43]. Indeed, melanoma tumors

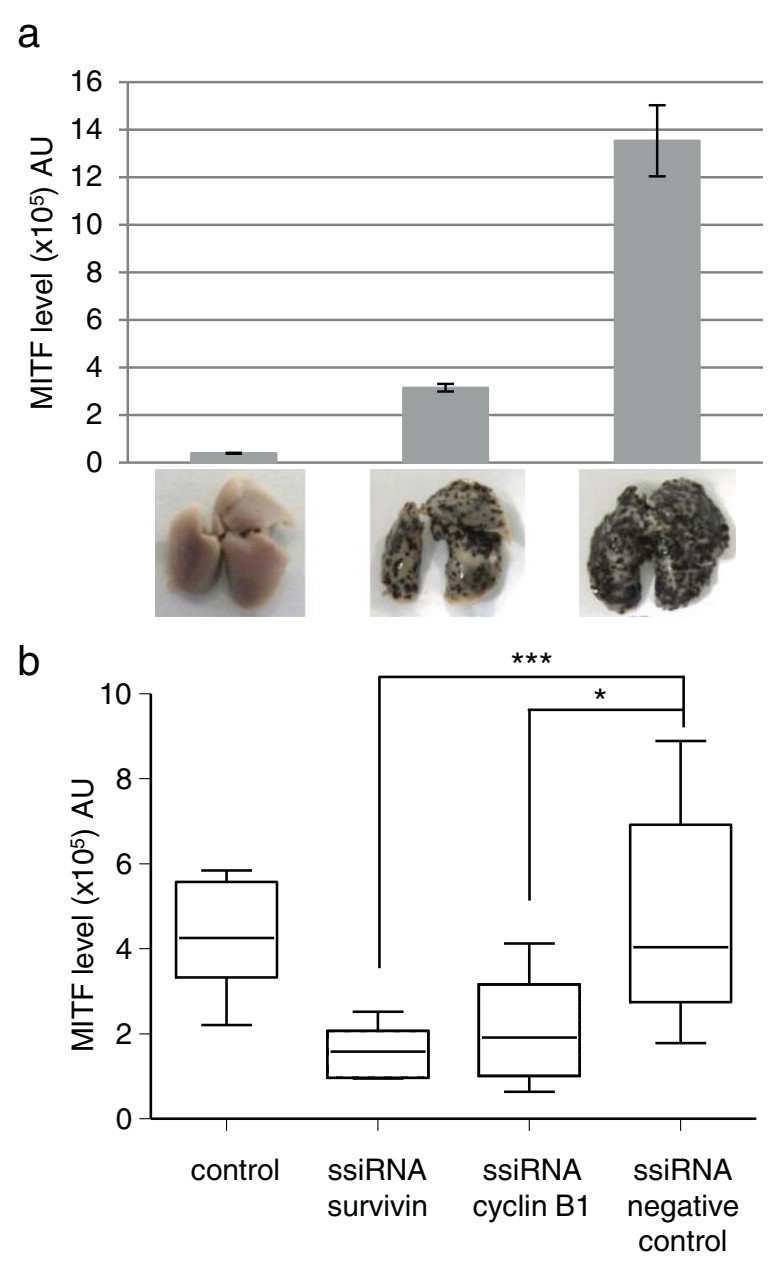

Figure 5 Quantification of the B16-F10 lung metastases using dosage of MITF melanocyte specific transcription factor expression. (a) Branched DNA analysis of RNA extracted from wild-type or B16-F10 tumor-bearing lungs for determination of MITF transcription factor mRNA expression level. (b) MITF RNA level was analyzed by branched DNA in B16-F10 tumor-bearing lungs untreated (control) or after a systemic treatment with survivin and cyclin B1 or negative control ssiRNA delivered with in vivo-JetPEl ${ }^{\circledR}$ ( $1 \mathrm{mg} / \mathrm{kg}, \mathrm{N} / \mathrm{P}=12.5) . \mathrm{n}=6$ to 9 animals per group. $\mathrm{P}$ values were calculated; * $p<0.05$; ${ }^{* *} p<0.001$.

are known to be partially refractory to doxorubicin [3], and high doses with subsequent toxic effects are necessary to induce tumor regression. Since survivin was shown to be a key factor in chemo-resistance, we hypothesized that a treatment with survivin ssiRNA could enhance the effect of doxorubicin on the inhibition of melanoma lung metastasis growth. In order to answer this question, we first established the optimal dose of doxorubicin, which would induce tumor growth inhibition with the least toxicity. To this end, three doxorubicin treatments (at day 4, 8 and 10) at three different doses $(1,2.5$ and $10 \mathrm{mg} / \mathrm{kg})$ were performed following B16-F10 tumor cells injection. Tumor growth inhibition was evaluated by lung weight and toxicity 
was determined by body weight loss during the course of the experiment. The treatment with doxorubicin at $1 \mathrm{mg} /$ $\mathrm{kg}$ was not toxic at all but had no effect on tumor growth either. On the other end, the $10 \mathrm{mg} / \mathrm{kg}$ dose was very efficient on lung tumors but induced a drastic body weight loss, almost $15 \%$ at the end of the experiment, accompanied by a general posture of the mice which was characteristic of a high toxicity (Figure $6 \mathrm{a}$ and $\mathrm{b}$ ). We thus retained the intermediate dose of $2.5 \mathrm{mg} / \mathrm{kg}$ which had only a mild effect on tumor growth inhibition but also shows minimal toxicity for the animals. We then evaluated the effect of an alternating treatment of doxorubicin and survivin ssiRNA compared to a treatment with either doxorubicin or survivin ssiRNA alone. The treatment with doxorubicin and ssiRNA was performed every alternate day as illustrated on Figure 6c. Doxorubicin $(2.5 \mathrm{mg} / \mathrm{kg})$ and survivin ssiRNA $(1 \mathrm{mg} / \mathrm{kg})$ had an additive effect on lung metastasis growth inhibition (Figure 6d). Whereas doxorubicin alone at $2.5 \mathrm{mg} / \mathrm{kg}$ was poorly efficient, its combination with survivin ssiRNA induced a significant metastasis inhibition as determined by a lung weight decrease compared to controls, and this without producing any toxicity. A strong diminution of the number and size of tumor nodules was observed visually (data not shown). Moreover, dosage of MITF mRNA level showed a $87 \%$ inhibition of tumor growth (MITF level, $0.6 \times 10^{5}+/-0.06 \times 10^{5}$ ) following the alternating treatment of doxorubicin and survivin ssiRNA compared to controls (MITF level, $4.3 \times 10^{5}+/-0.6 \times 10^{5}$ ) which was significantly higher than the survivin ssiRNA conditions without doxorubicin (54\% inhibition compared to control, MITF level, $\left.1.9 \times 10^{5}+/-0.4 \times 10^{5}\right)$.

These results are very encouraging for the development of survivin ssiRNA as a new strategy to circumvent the inherent chemo-resistance of melanomas or to enhance the chemosensitivity of melanomas. This combination therapy using ssiRNAs and chemotherapy offers a novel strategy for cancer treatment and is confirmed in other cancers $[44,45]$.

\section{Conclusion}

RNA interference is evolving as a promising strategy for cancer treatment. However, delivery of siRNAs in vivo

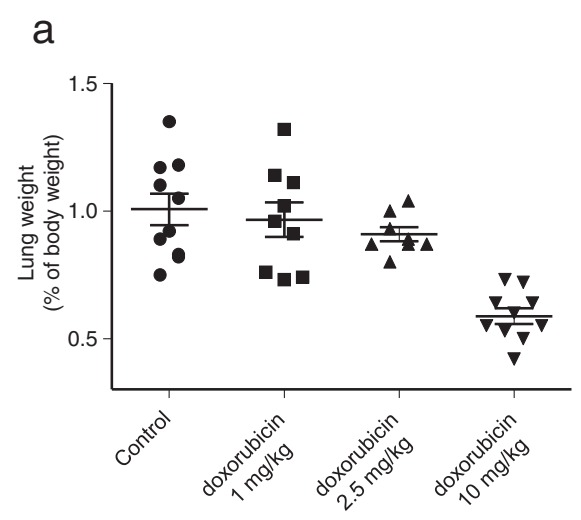

b

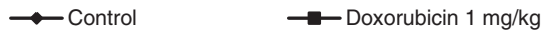

$\multimap$ Doxorubicin $2.5 \mathrm{mg} / \mathrm{kg} \rightarrow$ Doxorubicin $10 \mathrm{mg} / \mathrm{kg}$

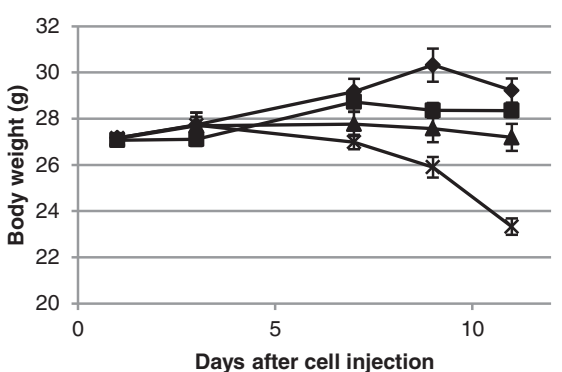

C

d

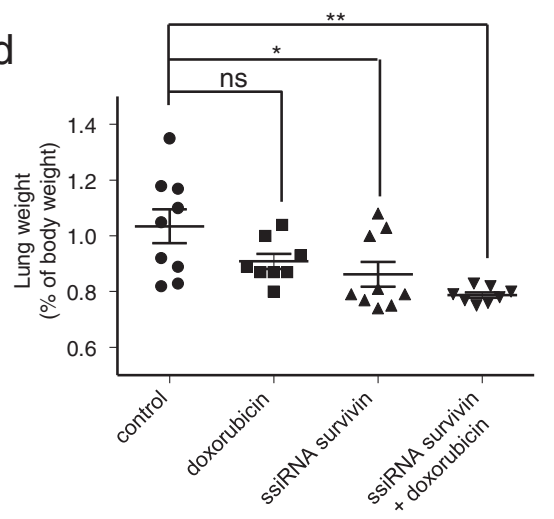

Figure 6 Additive effect of survivin ssiRNA and doxorubicin on the treatment of lung metastases. (a) Dose dependent effect of doxorubicin $(1,2.5$ or $10 \mathrm{mg} / \mathrm{kg})$ on lung metastasis growth assessed by the overall mean lung weight relative to the body weight of the mice. $\mathrm{n}=9$ animals per group. (b) Body weight measurement from the beginning to the end of the treatment was evaluated to determine the toxicity of doxorubicin treatments. (c) Schematic representation of the treatment procedure with doxorubicin alone, survivin ssiRNA alone, or both. (d) Overall mean lung weight relative to the body weight of the mice after an alternated treatment of doxorubicin and survivin ssiRNA with PEl, compared to treatment with doxorubicin or survivin ssiRNA alone. $n=9$ animals per group. $P$ values were calculated; ${ }^{*} p<0.05 ;{ }^{* *} p<0.01$. 
still remains the major issue for the development of a successful siRNA-based therapy. Our present study highlights an emerging RNAi technology, based on the use of sticky siRNAs delivered with PEI. These modified siRNAs, by mimicking gene structure, enhance siRNA delivery into cells and consequently lead to a better inhibition of genes involved in malignancies. In order to validate this new technology, we chose to design sticky siRNAs against two well-known players of the tumor progression process, survivin and cyclin B1 $[19,46,47]$. The results presented in this work demonstrate that PEI-mediated systemic delivery of sticky siRNAs against survivin and cyclin B1 lead to an efficient inhibition of tumor growth. Moreover, we showed in a previous study that no major inflammation is induced by linear PEI-mediated nucleic acid delivery in vivo, as neither pro-inflammatory cytokines nor hepatic enzymes were produced [48]. Altogether, these data are very encouraging for the clinical development of such therapies which could represent a promising approach for melanoma treatment.

\section{Additional files}

Additional file 1: Table S1. PCR conditions for $5^{\prime}$ RACE analysis.

Additional file 2: Figure S1. Linearity of MITF assay. Branched DNA analysis of RNA extracted from wild-type or B16-F10 tumor-bearing lungs to determine MITF mRNA expression level. Different volumes of lung extract $(0.1 ; 0.5 ; 1$ and $5 \mu \mathrm{l})$ were analyzed, showing a good linearity of the assay.

\section{Abbreviations}

ssiRNA: Sticky siRNA; PEl: Polyethyleneimine; N/P: PEl amine over nucleic acid phosphate charge ratio.

\section{Competing interests}

All the authors except Pattabhiraman Shankaranarayanan are employees of the Polyplus-transfection company, they declare no competing interests.

\section{Authors' contributions}

VK carried out in vivo and in vitro experiments, participated in the design of the study and drafted the manuscript, AM carried out in vivo experiments and participated in the design of the study, OZ carried out in vivo and in vitro experiments, MEB carried out in vivo and in vitro experiments, JBG carried out in vivo and in vitro experiments, EB carried out in vivo experiments, MM carried out in vitro experiments, PS gave some material and critically revised the manuscript, JPB participated in the design of the study and critically revised the manuscript, PE conceived the study, coordinated and helped to draft the manuscript, ALBB conceived the study, participated in its design and coordinated and helped to draft the manuscript. All authors read and approved the final manuscript.

\section{Acknowledgments}

We thank Dr Claire Wartel-Weil and Geraldine Guerin-Peyrou for critical reading of the manuscript. This work was supported by OSEO Innovation and Conseil Régional d'Alsace.

\section{Author details}

${ }^{1}$ Polyplus-transfection SA, Bioparc, BP 90018, Boulevard Sébastien Brant, 67401 IIlkirch, France. ${ }^{2}$ Current address: IBMC, 15 rue René Descartes, 67084 Strasbourg, France. ${ }^{3}$ IGBMC, 1 rue Laurent Fries, 67400 IIIkirch, France. ${ }^{4}$ Current address: Quintiles, rue Jean Dominique Cassini, BP 50137, 67404 Illkirch Cedex, France.
Received: 26 February 2013 Accepted: 1 July 2013

Published: 9 July 2013

\section{References}

1. Nguyen DX, Bos PD, Massague J: Metastasis: from dissemination to organ-specific colonization. Nat Rev Cancer 2009, 9(4):274-284.

2. Zheng Y, Fernando HC: Surgical and nonresectional therapies for pulmonary metastasis. The Surg Clin North Am 2010, 90(5):1041-1051.

3. Soengas MS, Lowe SW: Apoptosis and melanoma chemoresistance. Oncogene 2003, 22(20):3138-3151.

4. Ambrosini G, Adida C, Altieri DC: A novel anti-apoptosis gene, survivin, expressed in cancer and lymphoma. Nat Med 1997, 3(8):917-921.

5. Grossman D, McNiff JM, Li F, Altieri DC: Expression and targeting of the apoptosis inhibitor, survivin, in human melanoma. J Invest Dermatol 1999, 113(6):1076-1081.

6. McKenzie JA, Grossman D: Role of the apoptotic and mitotic regulator survivin in melanoma. Anticancer Res 2012, 32(2):397-404.

7. Altieri DC: Validating survivin as a cancer therapeutic target. Nat Rev Cancer 2003, 3(1):46-54.

8. Gradilone A, Gazzaniga P, Ribuffo D, Scarpa S, Cigna E, Vasaturo F, Bottoni U, Innocenzi D, Calvieri S, Scuderi N, et al: Survivin, bcl-2, bax, and bcl-X gene expression in sentinel lymph nodes from melanoma patients. J Clin Oncol 2003, 21(2):306-312.

9. Wheatley SP, McNeish IA: Survivin: a protein with dual roles in mitosis and apoptosis. Int Rev Cytol 2005, 247:35-88.

10. Thomas J, Liu T, Cotter MA, Florell SR, Robinette K, Hanks AN, Grossman D: Melanocyte expression of survivin promotes development and metastasis of UV-induced melanoma in HGF-transgenic mice. Cancer Res 2007, 67(11):5172-5178.

11. Mehrotra S, Languino LR, Raskett CM, Mercurio AM, Dohi T, Altieri DC: IAP regulation of metastasis. Cancer Cell 2010, 17(1):53-64.

12. McKenzie JA, Liu T, Goodson AG, Grossman D: Survivin enhances motility of melanoma cells by supporting Akt activation and \{alpha\}5 integrin upregulation. Cancer Res 2010, 70(20):7927-7937.

13. Pennati M, Folini M, Zaffaroni N: Targeting survivin in cancer therapy: fulfilled promises and open questions. Carcinogenesis 2007, 28(6):1133-1139.

14. Nakahara T, Kita A, Yamanaka K, Mori M, Amino N, Takeuchi M, Tominaga F, Hatakeyama S, Kinoyama I, Matsuhisa A, et al: YM155, a novel small-molecule survivin suppressant, induces regression of established human hormone-refractory prostate tumor xenografts. Cancer Res 2007, 67(17):8014-8021.

15. Talbot DC, Ranson M, Davies J, Lahn M, Callies S, Andre V, Kadam S, Burgess M, Slapak C, Olsen AL, et al: Tumor survivin is downregulated by the antisense oligonucleotide LY2181308: a proof-of-concept, first-in-human dose study. Clin Cancer Res 2010, 16(24):6150-6158.

16. Pennati M, Colella G, Folini M, Citti L, Daidone MG, Zaffaroni N: Ribozyme-mediated attenuation of survivin expression sensitizes human melanoma cells to cisplatin-induced apoptosis. J Clin Invest 2002, 109(2):285-286.

17. O'Connor DS, Grossman D, Plescia J, Li F, Zhang H, Villa A, Tognin S, Marchisio PC, Altieri DC: Regulation of apoptosis at cell division by p34cdc2 phosphorylation of survivin. Proc Natl Acad Sci USA 2000, 97(24):13103-13107.

18. Castedo M, Perfettini $J$, Roumier T, Kroemer G: Cyclin-dependent kinase-1: linking apoptosis to cell cycle and mitotic catastrophe. Cell Death Differ 2002, 9(12):1287-1293.

19. Soria JC, Jang SJ, Khuri FR, Hassan K, Liu D, Hong WK, Mao L: Overexpression of cyclin B1 in early-stage non-small cell lung cancer and its clinical implication. Cancer Res 2000, 60(15):4000-4004.

20. Hassan KA, Ang KK, El-Naggar AK, Story MD, Lee Jl, Liu D, Hong WK, Mao L: Cyclin B1 overexpression and resistance to radiotherapy in head and neck squamous cell carcinoma. Cancer Res 2002, 62(22):6414-6417.

21. Korenaga D, Takesue F, Yasuda M, Honda M, Nozoe T, Inutsuka S: The relationship between cyclin $B 1$ overexpression and lymph node metastasis in human colorectal cancer. Surgery 2002, 131:S114-S120.

22. Takeno S, Noguchi T, Kikuchi R, Uchida Y, Yokoyama S, Muller W: Prognostic value of cyclin B1 in patients with esophageal squamous cell carcinoma. Cancer 2002, 94(11):2874-2881.

23. Yasuda M, Takesue F, Inutsuka S, Honda M, Nozoe T, Korenaga D: Overexpression of cyclin B1 in gastric cancer and its clinicopathological 
significance: an immunohistological study. J Cancer Res Clin Oncol 2002, 128(8):412-416

24. Wang A, Yoshimi N, Ino N, Tanaka T, Mori H: Overexpression of cyclin B1 in human colorectal cancers. J Cancer Res Clin Oncol 1997, 123(2):124-127.

25. Kallakury BV, Sheehan CE, Rhee SJ, Fisher HA, Kaufman RP Jr, Rifkin MD, Ross JS: The prognostic significance of proliferation-associated nucleolar protein p120 expression in prostate adenocarcinoma: a comparison with cyclins A and B1, Ki-67, proliferating cell nuclear antigen, and p34cdc2. Cancer 1999, 85(7):1569-1576.

26. Allan K, Jordan RC, Ang LC, Taylor M, Young B: Overexpression of cyclin A and cyclin B1 proteins in astrocytomas. Arch Pathol Lab Med 2000 124(2):216-220

27. Kuhling $H, A$, $m$ P, Olsson $H$, Ferno $M$, Baldetorp B, Parwaresch R, Rudolph P: Expression of cyclins $E, A$, and $B$, and prognosis in lymph node-negative breast cancer. J Pathol 2003, 199(4):424-431.

28. Georgieva J, Sinha P, Schadendorf D: Expression of cyclins and cyclin dependent kinases in human benign and malignant melanocytic lesions. J Clin Pathol 2001, 54(3):229-235.

29. Yuan J, Yan R, Kramer A, Eckerdt F, Roller M, Kaufmann M, Strebhardt K: Cyclin B1 depletion inhibits proliferation and induces apoptosis in human tumor cells. Oncogene 2004, 23(34):5843-5852.

30. Ozeki M, Tamae D, Hou DX, Wang T, Lebon T, Spitz DR, Li JJ: Response of cyclin B1 to ionizing radiation: regulation by NF-kappaB and mitochondrial antioxidant enzyme MnSOD. Anticancer Res 2004, 24(5A):2657-2663.

31. Li Z, Xia L, Lee LM, Khaletskiy A, Wang J, Wong JY, Li JJ: Effector genes altered in MCF-7 human breast cancer cells after exposure to fractionated ionizing radiation. Radiat Res 2001, 155(4):543-553.

32. Bolcato-Bellemin AL, Bonnet ME, Creusat G, Erbacher P, Behr JP: Sticky overhangs enhance siRNA-mediated gene silencing. Proc Natl Acad SCi USA 2007, 104(41):16050-16055.

33. Yuan J, Kramer A, Matthess Y, Yan R, Spankuch B, Gatje R, Knecht R, Kaufmann M, Strebhardt K: Stable gene silencing of cyclin B1 in tumor cells increases susceptibility to taxol and leads to growth arrest in vivo. Oncogene 2006, 25(12):1753-1762.

34. Wolanin K, Magalska A, Mosieniak G, Klinger R, McKenna S, Vejda S, Sikora E, Piwocka $\mathrm{K}$ : Curcumin affects components of the chromosomal passenger complex and induces mitotic catastrophe in apoptosis-resistant Bcr-Ablexpressing cells. Mol Cancer Res 2006, 4(7):457-469.

35. Shrayer D, Bogaars H, Gersten D, Hearing V, Maizel A, Wanebo H: Nude mouse model to study passive humoral immunotherapy directed against B16 F10 murine melanoma. J Surg Oncol 1994, 57(1):50-56.

36. Altieri DC: Targeting survivin in cancer. Cancer Lett 2013, 332(2):225-228.

37. Dif F, Djediat C, Alegria O, Demeneix B, Levi G: Transfection of multiple pulmonary cell types following intravenous injection of PEI-DNA in normal and CFTR mutant mice. J Gene Med 2006, 8(1):82-89.

38. Zou SM, Erbacher P, Remy JS, Behr JP: Systemic linear polyethylenimine (L-PEI)-mediated gene delivery in the mouse. J Gene Med 2000, 2(2):128-134.

39. Ge Q, Filip L, Bai A, Nguyen T, Eisen HN, Chen J: Inhibition of influenza virus production in virus-infected mice by RNA interference. Proc Natl Acad Sci USA 2004, 101(23):8676-8681.

40. Gunther M, Lipka J, Malek A, Gutsch D, Kreyling W, Aigner A: Polyethylenimines for RNAi-mediated gene targeting in vivo and siRNA delivery to the lung. Eur J Pharm Biopharm 2011, 77(3):438-449.

41. Vachtenheim J, Borovansky J: "Transcription physiology" of pigment formation in melanocytes: central role of MITF. Exp Dermatol 2010, 19(7):617-627

42. Grossman D, Altieri DC: Drug resistance in melanoma: mechanisms, apoptosis, and new potential therapeutic targets. Cancer Metastasis Rev 2001, 20(1-2):3-11.

43. Hortobagyi GN: Anthracyclines in the treatment of cancer. An overview. Drugs 1997, 54(4):1-7.

44. Trabulo S, Cardoso AM, Santos-Ferreira T, Cardoso AL, Simoes S, de Lima MC P: Survivin silencing as a promising strategy to enhance the sensitivity of cancer cells to chemotherapeutic agents. Mol Pharm 2011, 8(4):1120-1131.

45. Chen S, Liu X, Gong W, Yang H, Luo D, Zuo X, Li W, Wu P, Liu L, Xu Q, et al: Combination therapy with VEGFR2 and EGFR siRNA enhances the antitumor effect of cisplatin in non-small cell lung cancer xenografts. Oncol Rep 2013, 29(1):260-268.

46. Velculescu VE, Madden SL, Zhang L, Lash AE, Yu J, Rago C, Lal A, Wang CJ, Beaudry GA, Ciriello KM, et al: Analysis of human transcriptomes. Nat Genet 1999, 23(4):387-388.

47. Dutta A, Chandra R, Leiter LM, Lester S: Cyclins as markers of tumor proliferation: immunocytochemical studies in breast cancer. Proc Natl Acad Sci USA 1995, 92(12):5386-5390.

48. Bonnet ME, Erbacher P, Bolcato-Bellemin AL: Systemic delivery of DNA or siRNA mediated by linear polyethylenimine (L-PEI) does not induce an inflammatory response. Pharm Res 2008, 25(12):2972-2982.

doi:10.1186/1471-2407-13-338

Cite this article as: Kedinger et al: Sticky siRNAs targeting survivin and cyclin B1 exert an antitumoral effect on melanoma subcutaneous xenografts and lung metastases. BMC Cancer 2013 13:338.

\section{Submit your next manuscript to BioMed Central and take full advantage of:}

- Convenient online submission

- Thorough peer review

- No space constraints or color figure charges

- Immediate publication on acceptance

- Inclusion in PubMed, CAS, Scopus and Google Scholar

- Research which is freely available for redistribution 